\title{
Composite encapsulation enabled superior comprehensive stability of perovskite solar cells
}

Yifan Lv, Hui Zhang*, Ruqing Liu, Yanan Sun, Wei Huang*

Key Laboratory of Flexible Electronics (KLOFE) and Institute of Advanced Materials (IAM)

Jiangsu National Synergetic Innovation Center for Advanced Materials (SICAM)

Nanjing Tech University (NanjingTech), 30 South Puzhu Road, Nanjing 211816, P. R. China

Corresponding e-mails: iamhuizhang@njtech.edu.cn; iamwhuang@,njtech.edu.cn 
Figure S1: Preparation scheme diagram

Figure S2: Cross-sectional SEM image

Figure S3:Contact angle measurement

Figure S4: EQE spectrum

Figure S5: Steady-state photocurrent

Figure S6: JV curves

Figure S7: XRD patterns

Figure S8: Stability under $60^{\circ} \mathrm{C}$

Figure S9: Stability under 1-sun illumination

Figure S10: Reversible phenomenon: control device

Figure S11: Reversible phenomenon: encapsulated device

Figure S12: Stability in ambient air

Figure S13: Stability under double 85 condition

Figure S14: photoluminescence microphotographs

Figure S15: Steady-state photocurrent: water immersion

Figure S16: SEM images and 3D AFM images 


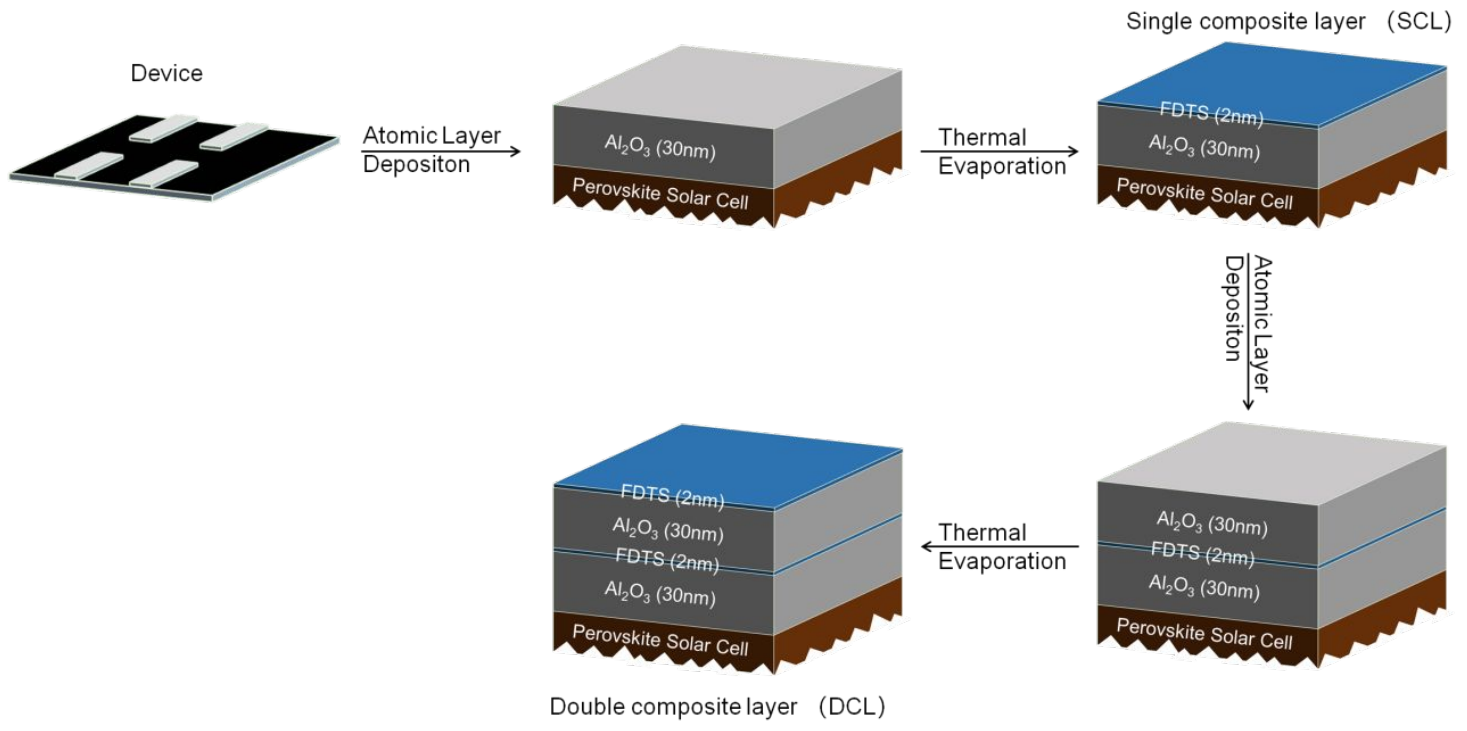

Figure S1. Preparation scheme diagram of SCL and DCL. 


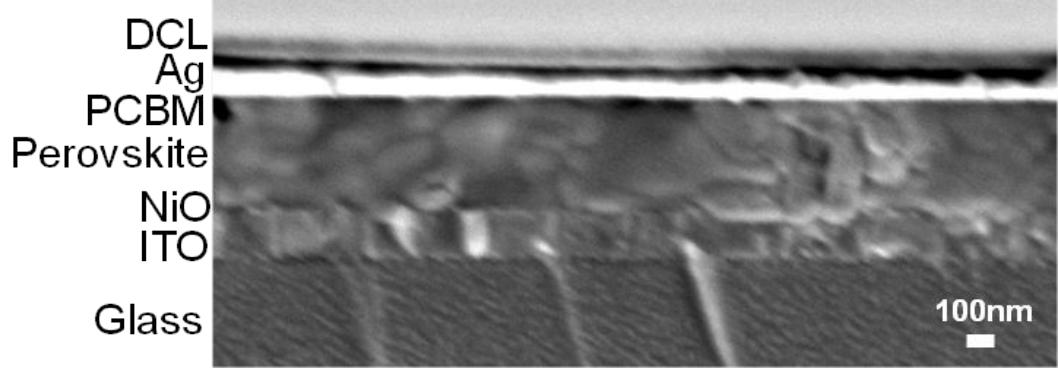

Figure S2. Cross-sectional SEM image of DCL encapsulated device. 
a

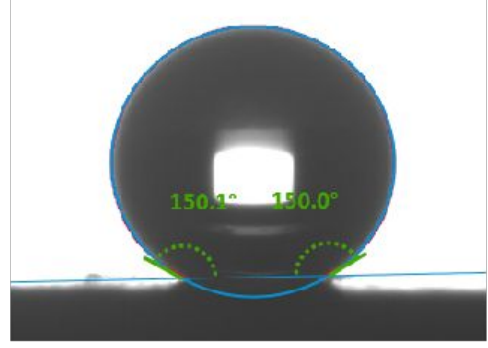

b

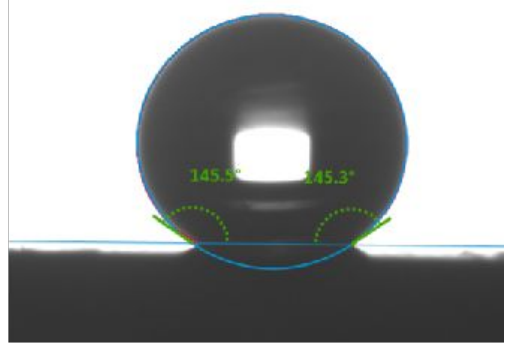

Figure S3. Water contact angle of a) DCL and b) SCL. 


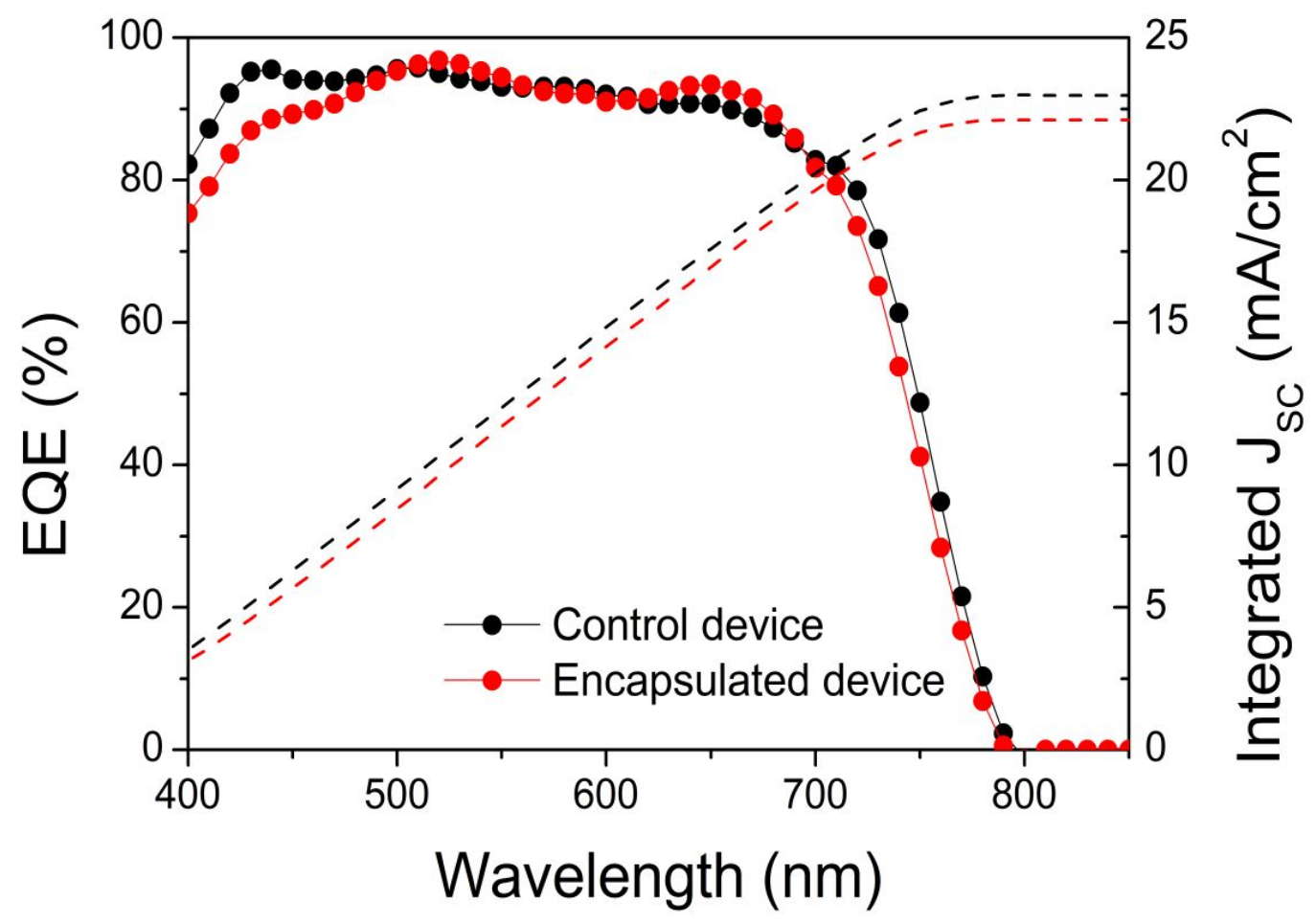

Figure S4. EQE spectrum of devices with (red) and without DCL encapsulation (black). 


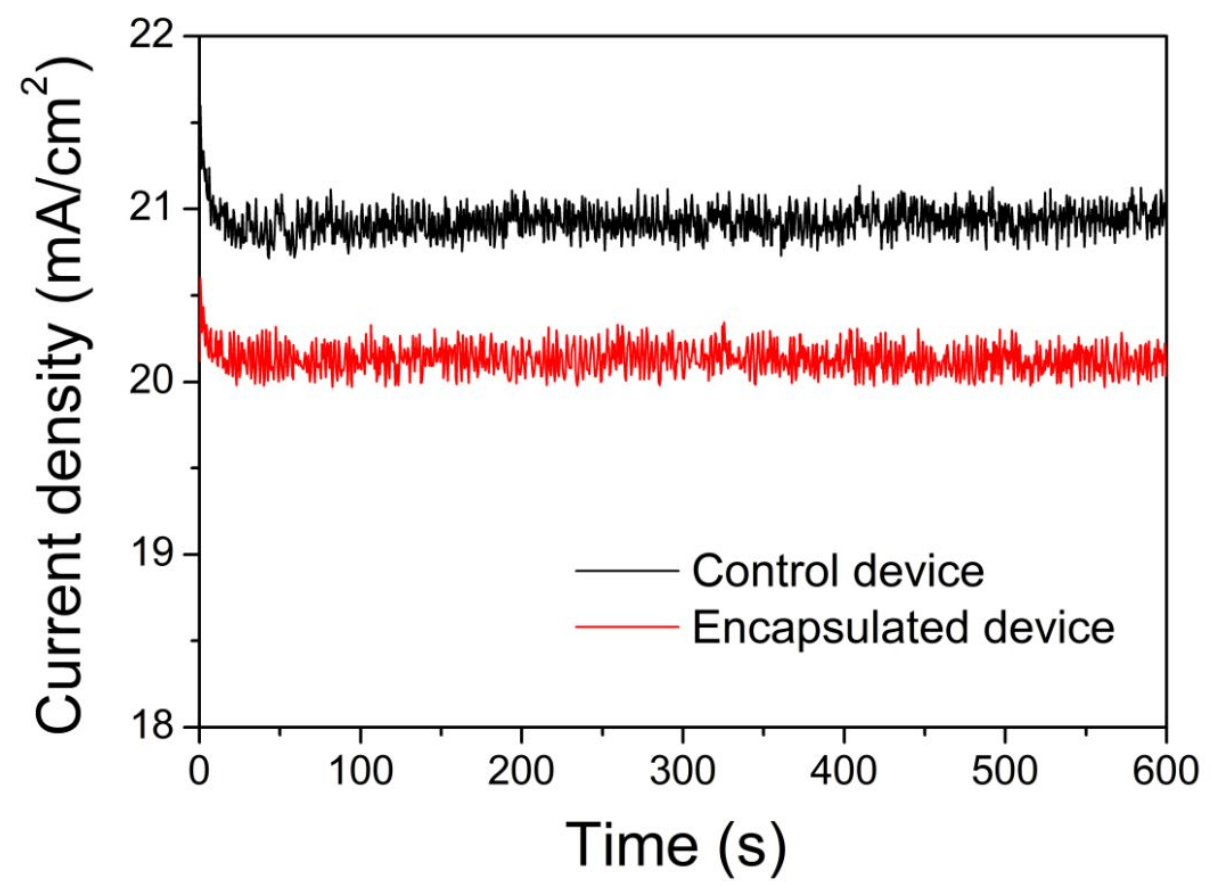

Figure S5. The steady-state photocurrent of devices with (red) and without DCL encapsulation (black). 


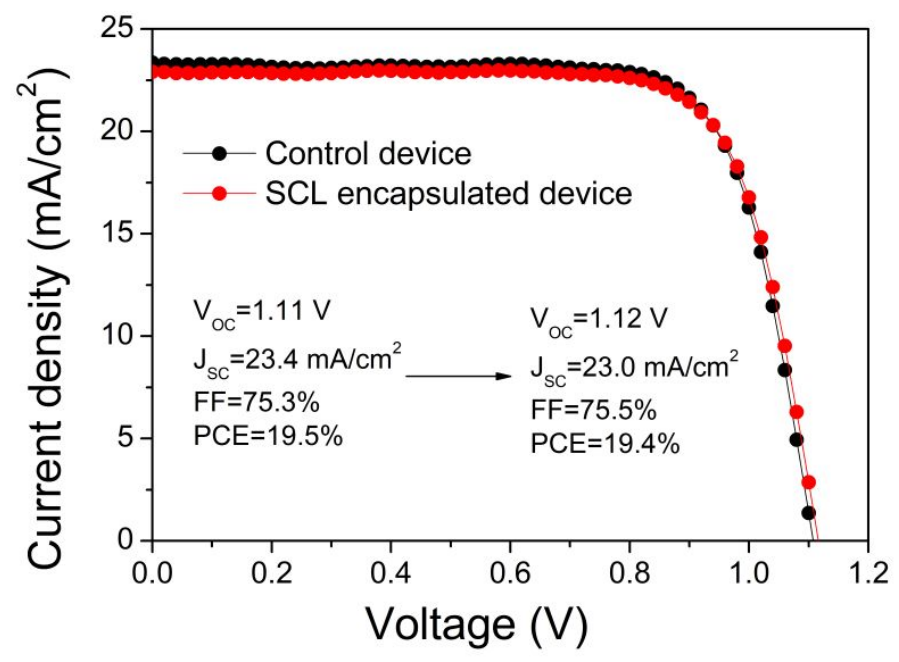

Figure S6. JV curves of the devices with (red) or without SCL (black). 


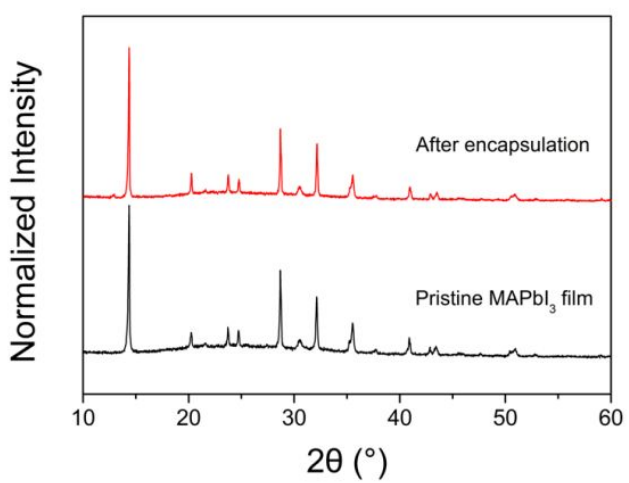

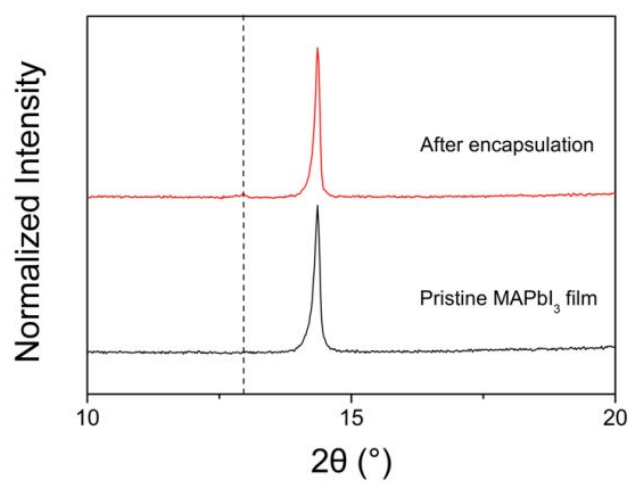

Figure S7. XRD patterns for $\mathrm{CH}_{3} \mathrm{NH}_{3} \mathrm{PbI}_{3}$ films before and after encapsulation, range from a) $10^{\circ}-60^{\circ}$ and b) $10^{\circ}-20^{\circ}$ 

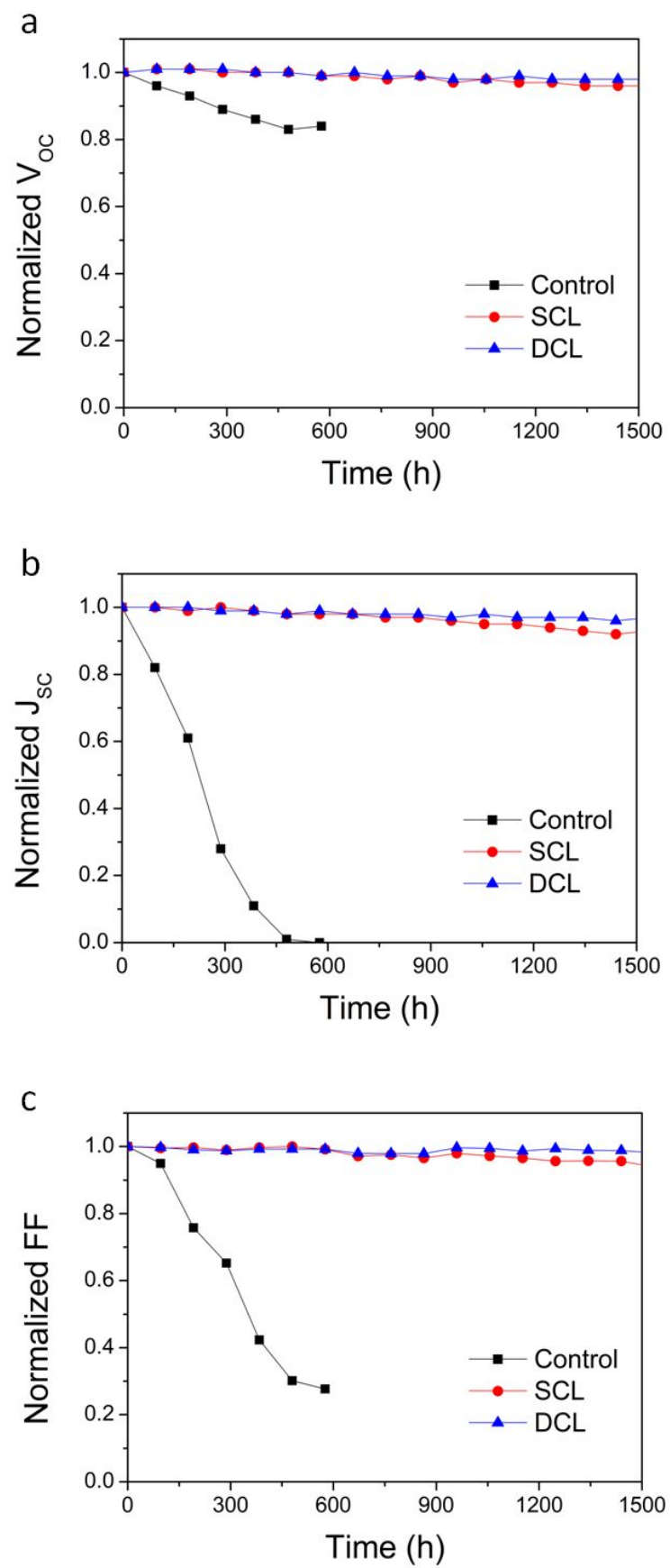

Figure S8. Normalized a) $\mathrm{V}_{\mathrm{OC}}$, b) $\mathrm{J}_{\mathrm{SC}}$ and c) FF evolution for the control device, SCL and DCL encapsulated perovskite solar cells under high temperature $\left(60{ }^{\circ} \mathrm{C}\right)$ aging in a $\mathrm{N}_{2}$ filled glovebox, from one device. 

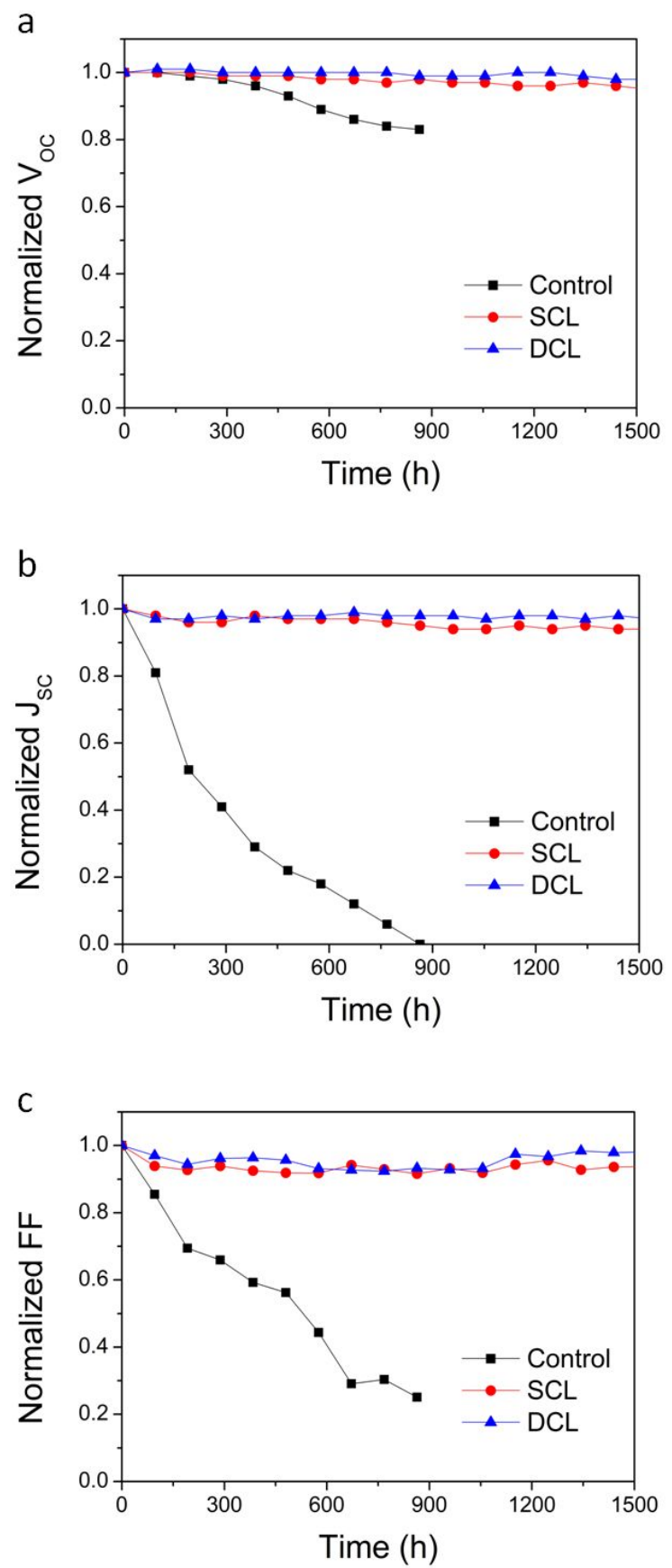

Figure S9. Normalized a) $\mathrm{V}_{\mathrm{OC}}$, b) $\mathrm{J}_{\mathrm{SC}}$ and c) FF evolution for the control device, SCL and DCL encapsulated perovskite solar cells under 1-sun illumination, from one device. 


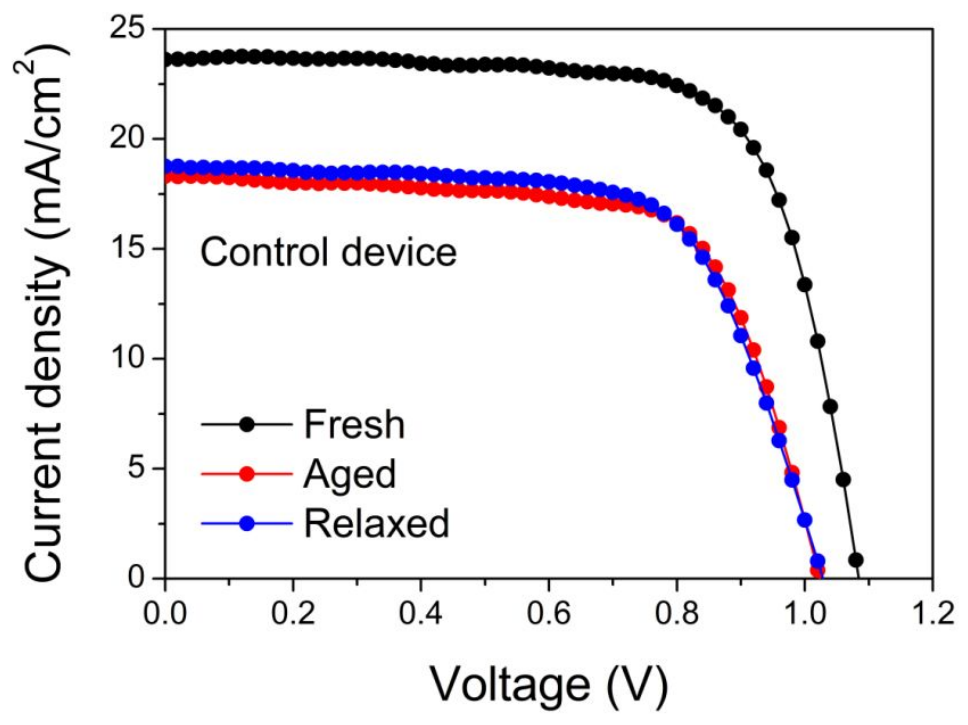

Figure S10. J-V curves for a fresh control device (black), the same device heated at $60^{\circ} \mathrm{C}$ for 200 hours (red) and the aged device placed in $\mathrm{N}_{2}$ without heat and light after 2 hours (blue). 


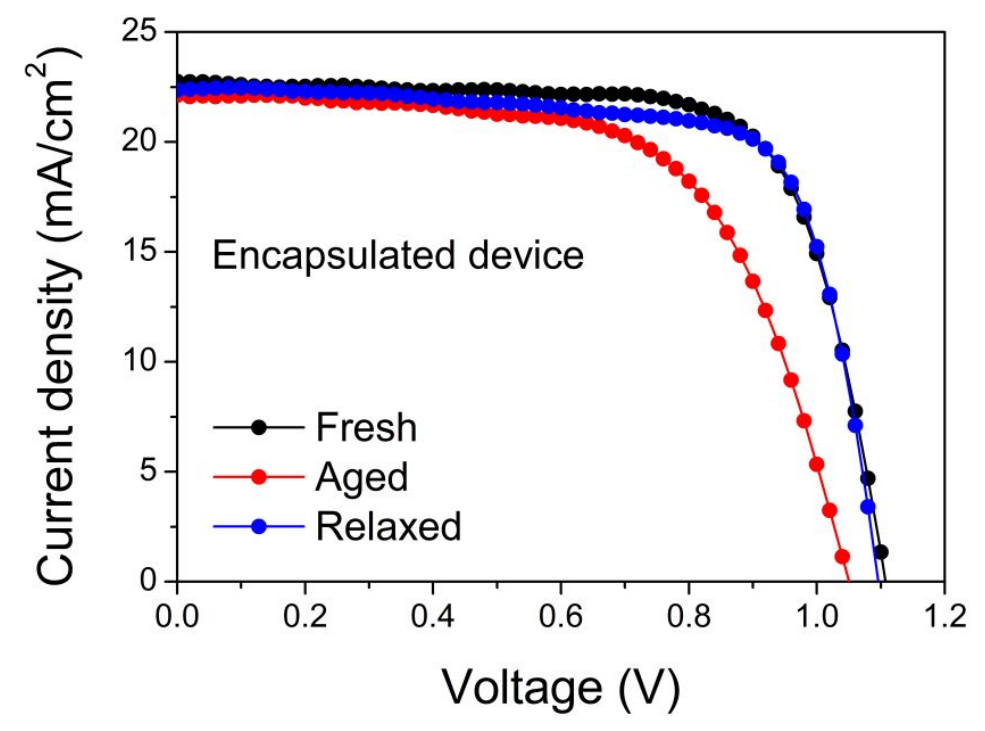

Figure S11. J-V curves for a fresh DCL encapsulated device (black), the same device heated at $60^{\circ} \mathrm{C}$ for 200 hours (red) and the aged device placed in $\mathrm{N}_{2}$ without heat and light after 2 hours (blue). 

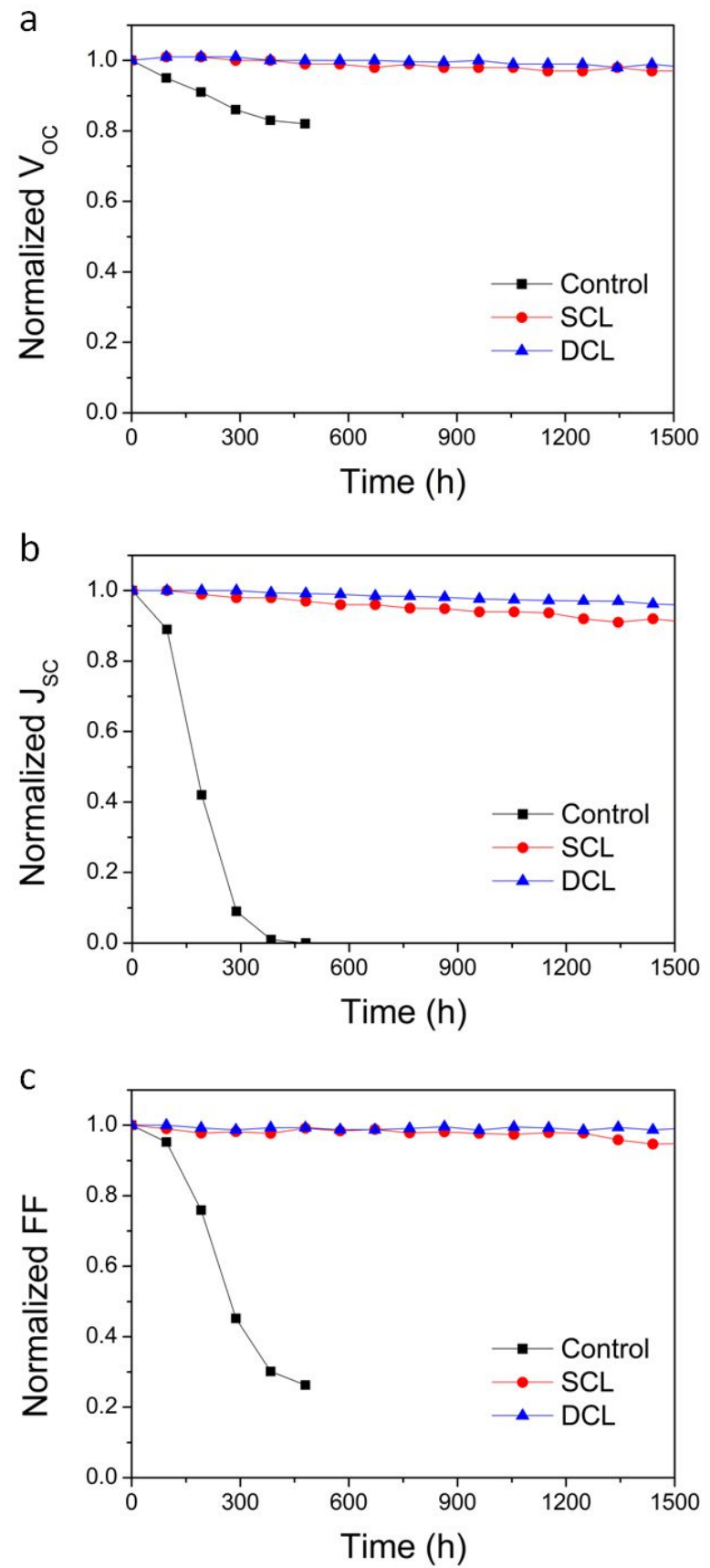

Figure S12. Normalized a) $\mathrm{V}_{\mathrm{OC}}$, b) $\mathrm{J}_{\mathrm{SC}}$ and c) FF evolution for the control device, SCL and DCL encapsulated perovskite solar cells in ambient air $\left(25^{\circ} \mathrm{C}, 50 \%\right.$ humidity $)$, from one device. 

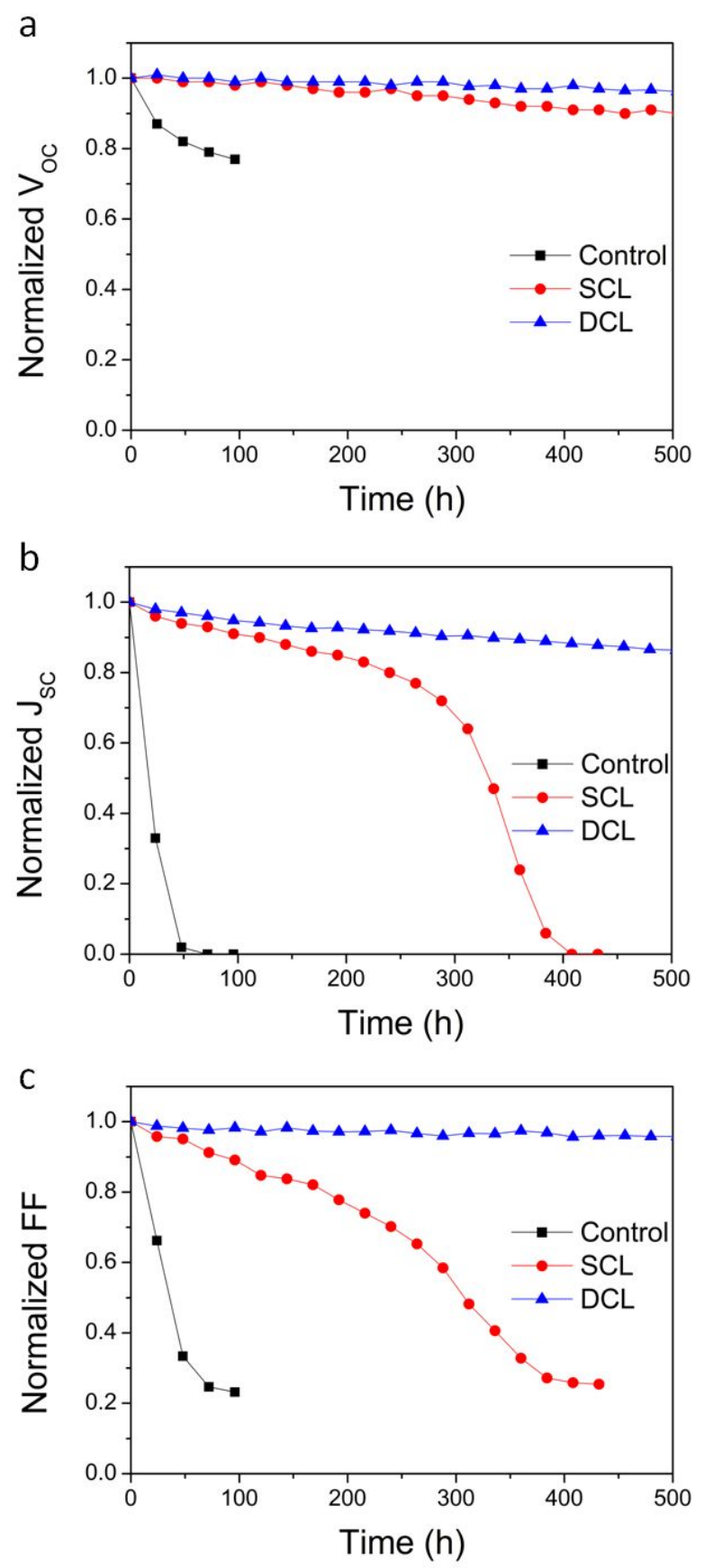

Figure S13. Normalized a) $\mathrm{V}_{\mathrm{OC}}$, b) $\mathrm{J}_{\mathrm{SC}}$ and c) FF evolution for the control device, SCL and DCL encapsulated perovskite solar cells under ambient air double 85 condition $\left(85^{\circ} \mathrm{C}, 85 \%\right.$ humidity), from one device. 


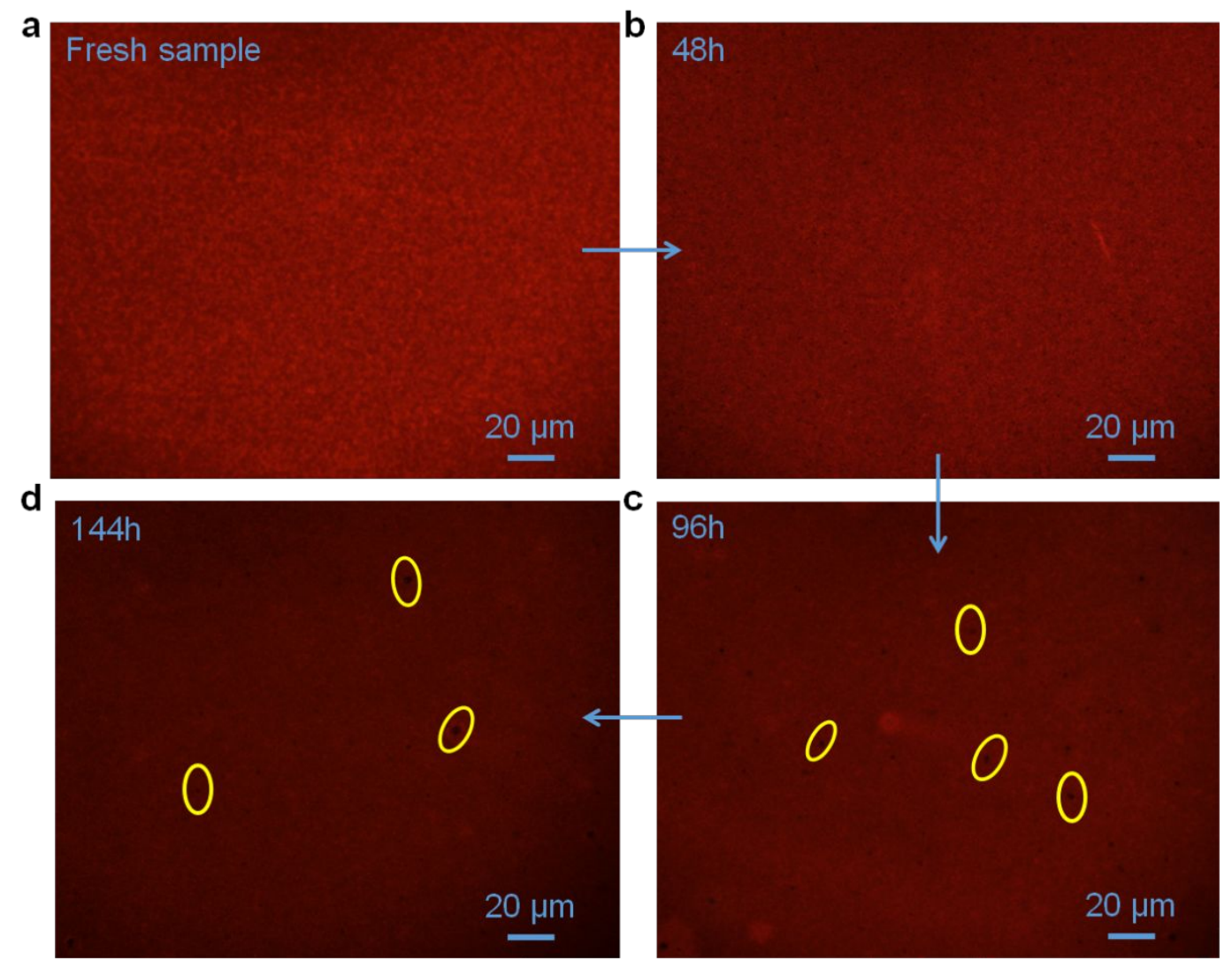

Figure S14. Photoluminescence microphotographs of encapsulated perovskite films, stored under double 85 condition for different times. 


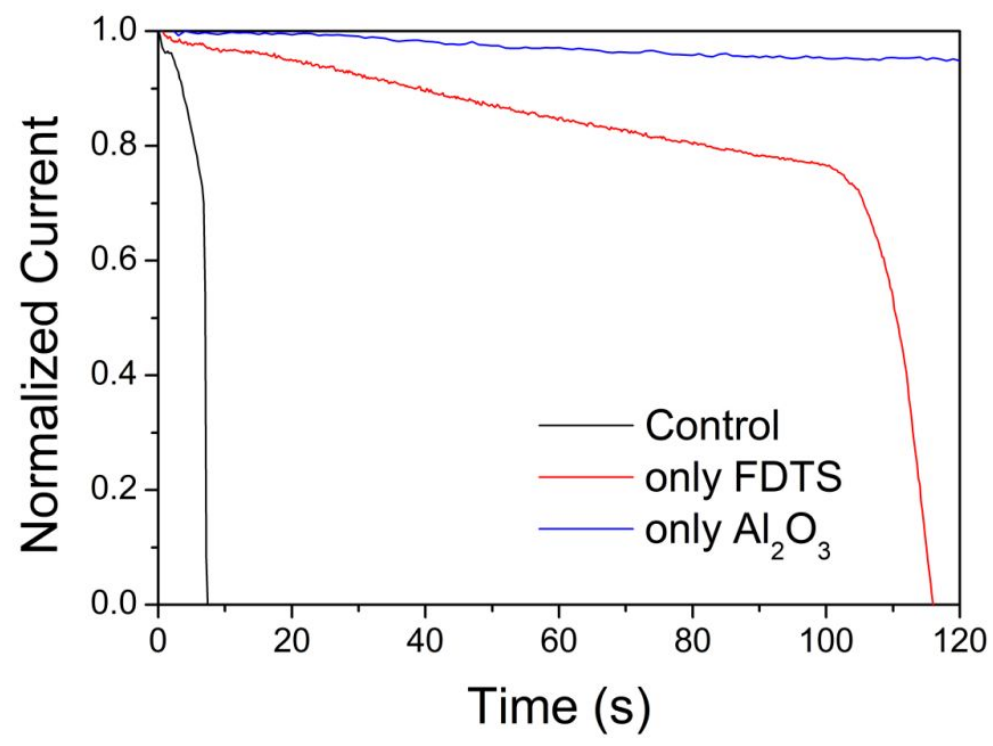

Figure S15. The steady-state photocurrent at maximum power point of the control device, device with only FDTS and device with only $\mathrm{Al}_{2} \mathrm{O}_{3}$ being immersed in water. 

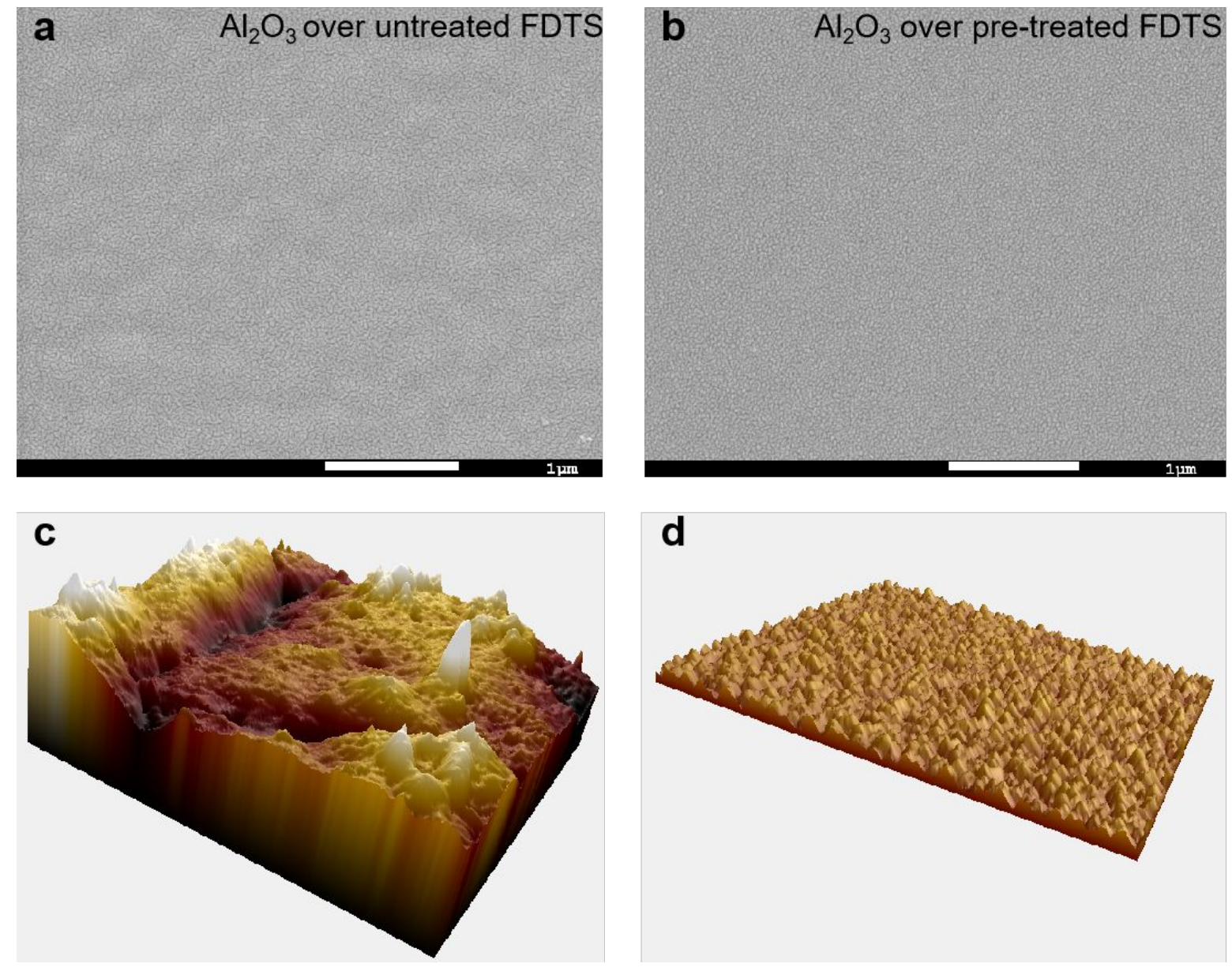

Figure S16. SEM images $(\mathrm{a}, \mathrm{b})$ and 3D AFM images $(\mathrm{c}, \mathrm{d})$ of $\mathrm{Al}_{2} \mathrm{O}_{3}$ over untreated FDTS $(\mathrm{a}, \mathrm{c})$ and pre-treated FDTS $(\mathrm{b}, \mathrm{d})$, respectively.

SEM and 3D AFM of $\mathrm{Al}_{2} \mathrm{O}_{3}$ over untreated FDTS and pre-treated FDTS were carried out to show the morphology of $\mathrm{Al}_{2} \mathrm{O}_{3}$, respectively. And we found the $\mathrm{Al}_{2} \mathrm{O}_{3}$ over untreated FDTS had a very rugged surface while the surface of $\mathrm{Al}_{2} \mathrm{O}_{3}$ over pre-treated FDTS was flat and uniform. We speculated that the rugged surface was resulted from an incompact deposition of $\mathrm{Al}_{2} \mathrm{O}_{3}$ over hydrophobic FDTS. 